\title{
Distinct and untamed: Articulating bulimic identities
}

\section{Citation:}

Eli, K. (forthcoming). Distinct and untamed: Articulating bulimic identities. Culture, Medicine, and Psychiatry.

Publisher's version:

DOI: $10.1007 / \mathrm{s} 11013-017-9545-8$

Author:

Karin Eli

Institute of Social and Cultural Anthropology, University of Oxford 


\section{Abstract}

Bulimia nervosa and anorexia nervosa are inextricably linked, with substantial clinical and epidemiological overlaps. Yet, while anorexia has been analyzed extensively in medical anthropology, bulimia remains under-theorized. This is, perhaps, because, compared to selfstarvation, binge eating presents a logic of practice that is difficult to reconcile with culturally reified notions of self-control, transcendence, and hard work. Thus, although anthropologists have analyzed anorexic subjectivities as imbued with a sense of cleanliness and purity, moral superiority, and heroics, similar analyses have not been extended to bulimic subjectivities; instead, bulimia has been subsumed, as a tangential disorder, into analyses of anorexia. In this paper, I aim to move bulimic identities from the margins to the centre of anthropological analysis. Based on participant narratives, I analyze bulimic identity as articulated by six Israeli women who identified as bulimic and received treatment for bulimia. The women's narratives show that bulimic identity is aligned with concepts of distinct selfhood. For these women, to be bulimic was to be framed as 'abnormal'; but this 'abnormality', albeit a source of social stigma and shame, held meanings that went beyond pathology. Through the claiming of bulimic identity, the women positioned themselves as untamed, non-conforming subjects, who acted against gendered and classed expectations - and even against the limitations of the body. Their constructions of bulimic distinction highlight the need for anthropological work that situates bulimia not as a footnote to anorexia, but as a structurally and culturally meaningful disorder in its own right.

Keywords: Bulimia nervosa; eating disorders; illness narratives; Israel; medical anthropology 


\section{Introduction}

Bulimia nervosa and anorexia nervosa are inextricably linked. ${ }^{1}$ Despite their DSM (American Psychiatric Association, 2013) and ICD (World Health Organisation, 1992) definitions as discrete clinical entities, and notwithstanding popular and scholarly imaginings of the two disorders as polar opposites, in the experience of most people with eating disorders, one implicates the other. As numerous clinical studies have found, in patients' illness trajectories, anorexia often turns into bulimia - and movement from bulimia to anorexia, while less common, also occurs in a sizable percentage of cases (Eddy et al., 2008). Moreover, dietary restriction - the hallmark practice of anorexia - occurs with high frequency among most people with bulimia (Elran-Barak et al., 2015). Likewise, the hallmark practices of bulimia, binge eating and purging (which may include vomiting, use of diuretics or laxatives, and other compensatory practices), are common among people with anorexia (Eddy et al., 2002); indeed, in the DSM-V (American Psychiatric Association, 2013), anorexia nervosa has two subtype classifications: restricting type and bingeing and purging type.

These clinically and epidemiologically documented overlaps between the two disorders also gain expression in the narrated lived experiences of people with anorexia and/or bulimia. Anthropological work on eating disorders has acknowledged the co-implication of bulimia and anorexia. Helen Gremillion (2003), Rebecca Lester (2007; 2014), and Anna Lavis (2011) have written about patients who were diagnosed with bulimia or with both anorexia and bulimia, although they did not focus on these participants' bulimic experiences. Megan Warin (2010) has noted the fluid relationship between anorexia and bulimia, and highlighted the participants' sense that - despite this fluidity - bulimia was "lower down the scale" compared to anorexia, due to the presumed "messiness and weakness" it evinces (p. 94). However, despite recognizing the kinship between the two disorders, anthropological analysis - like social theoretical analysis (e.g. Hepworth, 1999; Bordo, 2003) - has left bulimia undertheorized. Anorexia remains the focus of anthropological texts on eating disorders, where the experiences of people with bulimia, when not entirely excluded, are folded under the 'anorexia' heading. This is quite a literal process, apparent in the titles of most anthropological writings on eating disorders: the three anthropology monographs on eating disorders are titled Feeding anorexia: Gender and power at a treatment center (Gremillion, 2003), Abject relations: Everyday worlds of anorexia (Warin, 2010), and From virtue to vice: Negotiating anorexia (O'Connor and Van Esterik, 2015); many anthropological journal articles and book chapters on eating disorders also name anorexia in their titles, excluding bulimia (e.g. Shohet, 2007; Gooldin, 2008; Lavis, 2016). ${ }^{2}$

\footnotetext{
${ }^{1}$ From here on, I use the abbreviations 'anorexia' and 'bulimia', except when directly referring to the psychiatric codification of these disorders.

${ }^{2}$ This list was inspired by Sarah Squire's (2003) exercise, in which she named the titles of major feminist theory texts on eating disorders, to reveal their bias toward anorexia.
} 
Although anthropological analyses have attended to the meanings of self-starvation as culturally, historically, and phenomenologically situated (e.g. Lester, 1997; Warin, 2010), they have paid little scholarly attention to binge eating practices. Explorations of binge eating have been largely relegated to clinical studies, where binge eating has been framed as a means of ameliorating negative moods or as a cognitively maladaptive response to 'failure' at dietary restriction (Alpers \& Tuschen-Caffier, 2001; Fairburn et al., 2003). The few interview-based analyses of bulimic women's lived experiences, conducted by nursing and psychology researchers, have focused on the discursive construction of bulimia as a counterpoint to anorexia (see Burns, 2004), or on women's differing interpretations of their bulimic practices as self-victimizing, abject (see Brooks at al., 1998), and shameful (Broussard, 2005). When analyses of binge eating appeared in anthropology and social theory, this practice was invoked as a politically-loaded metaphor: for Susan Bordo (2003), the binge was the postmodern feast that must be consumed before the obligatory purge; for Nancy Scheper-Hughes and Margaret Lock (1987 [commenting on Crawford, 1985]), it was the manifestation of consumerist engorgement. The only exceptions to this line of analysis were provided by Becky Thompson (1992), who analyzed binge eating as sedative, with food as a cheap drug, abused to cope with racist, heterosexist, and classbased oppression, and by Sarah Squire (2003), who theorized binge eating as "habit and habitat" (p. 17).

The absence of binge eating from anthropological and cognate analyses reveals the difficulty of theorizing bulimia. The bulimic body, being of average or over-weight, is imbued with socially invisible, even stigmatized, suffering (Squire, 2002). Compared to self-starvation, binge eating presents a logic of practice that is difficult to reconcile with culturally reified notions of self-control, transcendence, and hard work. This does not imply that anorexic self-starvation is portrayed and analysed as the conformist embodying of cultural values; on the contrary, the popular media frequently frame anorexic practice - and in particular pro-anorexic discourse - as deviant, dangerous, and contagious (Lavis, 2014), while feminist readings of anorexic self-starvation position it as a form of resistance against the patriarchal equating of women with the body and its 'inferior' desires (Heywood, 1996; Bordo, 2003). The appeal of theorizing self-starvation compared to binge eating, then, lies not in an ascription of self-starvation to cultural conformity, but rather in the analytic alignment of this practice with long-standing ontologies of bodies and selves. As Squire (2003) argues, bulimia does not lend itself to theoretical models of disciplined feminine bodies, bearing the scars of millennia of Christian asceticism and mind-body dualism (e.g., Bordo, 2003). Thus, while anthropologists have analyzed anorexic subjectivities as imbued with a sense of cleanliness and purity (Warin, 2010), moral superiority (O’Connor and Van Esterik, 2015), and heroics (Gooldin, 2008), similar analyses could not be extended to bulimic subjectivities. The conceptual complexity presented by bulimia has been met, thus far, with little theorizing. 
The under-theorizing of bulimia and binge eating - and the binary framing of anorexia and bulimia sharply contrasted with the narrated experiences of many of the women who took part in my study. In late 2005, soon after I began my longitudinal research on the eating disordered experience, I found that binge eating was a formative experience for many of the 36 participants, across all eating disorder diagnoses - anorexia nervosa, bulimia nervosa, and eating disorder not otherwise specified. Based on the narratives of the 16 participants who discussed practices and experiences of binge eating, I wrote an article that explored binge eating as a meaningful practice. While the participants were acutely aware of the social stigmatization of binge eating - indeed, some participants expressed disgust with this practice - their descriptions of embodying binge eating positioned the so-called 'loss of control' involved in the binge as a form of self-expression and self-protection, a necessary antidote to the 'imprisonment' of self-starvation and to the social and emotional pain of everyday existence (see also Eli, forthcoming). For these participants, binge eating held literalized, embodied meanings of fullness and release - meanings powerful enough to sustain this practice for years, and even decades (Eli, 2015). I argued, then, that binge eating has an internal logic: it follows culturally and linguistically constructed notions of being-in-the-world, allowing people to move from existential, felt states of constraint and emptiness, into - albeit temporary - embodied sensations of release, authenticity, and living a full life.

While my analysis offered an understanding of binge eating as a meaningful practice, I was left with another question: why did some participants contest and negotiate the diagnosis of bulimia, while others proclaimed it, directly identifying as bulimic, sometimes even embracing that identity? Of the 16 women, eight contested or negotiated bulimia as a diagnosis, two mentioned a past diagnosis of bulimia with which they no longer identified, and six identified as bulimic or as having bulimia. Through analysing the narratives of these six participants, I aim to understand what constitutes bulimic identity, as constructed at the intersections of bulimia as lived experience and bulimia nervosa as a biomedically diagnosed disorder. Namely, I ask: how does the claiming of bulimia as a diagnosis connect with narrative constructions of practice and self?

\section{Methods}

This article draws on interview data collected as part of a longitudinal study on the eating disordered experience in Israel (2005-2006 and 2011). The first phase of the study included 36 participants (35 women and one man, all Jewish Israelis), of whom 16 women spoke about experiences of binge eating. Of these 16 participants, six identified as bulimic or as having bulimia; the interviews of these six participants were therefore selected as the focus of analysis in this article. I met with four of these six participants again in 2011; however, this article draws on the data collected in 2005-2006, as the earlier interviews focused on the construction of illness and recovery narratives, while the latter interviews focused on processes of chronicity and recovery that took place in the intervening years. 
Participant recruitment for the study took part through three main sources: an informal network led by the study's key participant, a pro-recovery Hebrew language eating disorders discussion board, and an outpatient eating disorders clinic. The process of participant recruitment through these three sources has been described in detail elsewhere (Eli, 2014). Of the six participants on whom this article focuses, two were recruited through the informal network, two through the discussion board, and two through the eating disorders clinic. At the time of first interview, the participants ranged in age from 21 to 38 years old - a range similar to the larger sample. All had long-term eating disorders (six or more years at first interview), and had been clinically diagnosed and treated; four of the women had been hospitalized in inpatient eating disorders or general psychiatric wards. At the time of first interview, one woman was acutely ill, two women identified as recovered, and three as recovering; the women's degrees of recovery varied substantially, from making the initial steps toward ending eating disordered practice to marking several years since the last bingeing and purging episode.

Data were collected through semi-structured interviews, designed to co-produce narratives of each participant's illness and recovery. While participants were asked similar core questions (e.g. "how do you define yourself with respect to the illness?"), the interviews were conversational and followed the participants' narrative directions. While I employed biomedical terms in some questions - for example, using the words "illness" or "disorder" - these terms were not prescriptive, and participants engaged in contestation and negotiation of biomedical terminologies and frameworks. Notably, I did not ask participants directly if they were diagnosed with bulimia, and I only asked participants about experiences of binge eating after they had mentioned engaging in this practice. The interviews took place in locations the participants chose (their homes, a park, a shopping mall, and cafes) in the Tel Aviv, Jerusalem, Sharon, and Shfela regions; they were digitally recorded and transcribed. For this analysis, I extracted the interview segments in which the participants who engaged in binge eating spoke of bulimia or of their eating disordered identities. Based on these extracts, I identified the six participants who described themselves as bulimic. As I was specifically interested in exploring participants' articulations of bulimic identities, I extracted further segments from these participants' interviews in which they characterized themselves or others in relation to bulimic practices. Using a thematic analysis approach (Braun and Clarke, 2006), I analysed the extracts to identify sub-themes across the subsample of six, and then grouped the sub-themes under three thematic categories, which I present in this paper. The extracts included in this paper are my own translations from the original Hebrew. In translating these extracts, I aimed to reproduce the participants' vocabulary and grammatical constructs as closely as possible.

The study received ethics approval from my university in 2005 and 2011, and ethics approval from an Israeli health care fund Helsinki ethics committee in 2005 (Helsinki ethics approval was not needed in 2011). The participants provided written informed consent. All names used in this article are 
pseudonyms, and identifying details have been concealed or altered.

\section{The themes}

Three themes were identified through the analysis: (1) proclaiming bulimic identity, (2) bulimic being as distinct, and (3) from abnormal to untamed selfhood. In the first theme, I examine how participants employed the terms 'bulimic' or 'bulimia' in their narratives. The theme begins by exploring how participants from the larger sample contested bulimia in their narratives, and then focuses on how the six participants who identified as bulimic proclaimed bulimia in their narratives. In the second theme, I turn to the participants' construction of bulimic selfhood as inherently relational, cast in opposition to anorexia and to health. This theme highlights how bulimic identity, as defined vis-à-vis diagnosis, interwove with participants' narrative constructions of experience and self. Finally, in the third theme, I explore how participants repositioned pathologized constructions of bulimic being to experience themselves as non-conformist, subversive subjects. This theme thereby demonstrates how participants aligned bulimia with concepts of socially valued selfhood.

\section{Proclaiming bulimic identity}

The 16 participants who spoke of binge eating had a range of diagnoses. Diagnosis was fluid - some participants were diagnosed with both anorexia and bulimia simultaneously (during the era of the DSM III-R [American Psychiatric Association, 1987]); others moved from one diagnosis to another (and back again); and still others were never diagnosed with bulimia. But diagnosis did not equal identity. As mentioned in the introduction, of the 16 women, eight contested bulimia as an actual or possible diagnosis. Among these participants, one transitioned during her interview from describing herself as bulimic to saying that she did not use that word, two identified as having had both bulimia and anorexia, but said "(I was) like all the anorexics in the books" (Orit) or "I was anorexic in my head" (Tamar), and the others explained why they were not bulimic although they might be considered as such. The negotiation of bulimia took a number of discursive forms. Some participants focused on particular practices, either binge eating or purging, as proof that they were not bulimic. For example, Stav, a participant who was diagnosed with bulimia, said:

It's possible to call it a half bulimia, because it's not - it's not daily... it's rare, rare that there's a day when I don't vomit, but it's not a binge. And bulimia is a binge. (Stav)

By contrast, Rinat, who identified as anorexic, defined bulimia through the act of purging:

I had lots of binging attacks. I wouldn't vomit after, like a bulimic, but I knew my weight was okay, so I allowed myself to eat, I would eat lots.... Like, a normal human being can never 
put these amounts into his stomach, never, it's crazy. (Rinat)

Other participants focused on the moral associations of bulimia when explaining why they stood at some distance from this diagnosis. Ma'ayan explained that she actively avoided purging following binges because she "didn't want to be considered bulimic (...) I didn't want to be considered sick". Aline, who said she sought treatment for anorexia only after she began binge eating, explained that "a bulimic is an anorexic who failed, and I had no intention of failing". These negotiations of bulimia as a diagnosis were not surprising. As Squire (2003) writes, bulimia is culturally framed as anorexia's 'other', the 'danger' to its 'purity'. The same cultural forces that cultivate "desire for anorexia" (Lavis, 2016) are the forces that index bulimia as shameful, to be hidden away and left unclaimed.

Yet, six of the participants described themselves as bulimic. This was not simply a matter of diagnosis - two were diagnosed with anorexia and bulimia at the same time, and one developed bulimia following hospitalization for anorexia. For most, narratives of emergent eating disorder (either bulimia, or the anorexia that preceded it) were embedded in narratives of adolescent participation in Israeli institutions of 'good citizenship', including a kibbutz, a youth movement, an elite secondary school, and the Israeli Defense Forces (where compulsory service begins at age 18). The women's possibilities within these institutions, however, were conditioned by structural elements that subsequently wove into their discursive constructions of bulimic identity. A recurrent theme across their recollections of emergent eating disorders was that of not integrating successfully into a total institution despite attempting to belong (see also Eli, forthcoming). For some participants, these experiences of not belonging were directly related to marginalized ethnicity and social class. Mirah linked the emergence of her eating disorder to a nascent recognition of her marginalized status as a Mizrahi (Middle Eastern Jewish) girl, within the overwhelmingly Ashkenazi (Eastern and Central European Jewish) context of her adolescent peer group. Adi, who was also Mizrahi and working class, located the beginnings of her eating disorder in the class-related shame she experienced at her high school - and later, when she tried and failed to be assigned to an elite military unit. Among participants of middle class backgrounds, social class also appeared as an influential, albeit less overt, backdrop: for example, Shiri, who was assigned an elite military role, linked the worsening of her bulimia to feeling less clever and successful than her fellow soldiers, and to the consequent isolation and invisibility she experienced at her military base. An exception to these narratives of failing to integrate into normative institutions was Angie, who grew up in poverty and was excluded entirely from institutional 'good citizenship', having developed bulimia within the confines of a closed paediatric psychiatry ward, where she was hospitalized in early adolescence following a suicide attempt. While these experiences of social difference, moulded through institutional inclusion and exclusion, were not unique to participants who identified as bulimic (and, indeed, occurred among participants who identified as anorexic), they shed light on the locally specific contexts of sociality 
and citizenship within which participants constructed bulimic identities.

Although the six women who described themselves as bulimic situated their bulimic identities with reference to social contexts, they simultaneously employed biomedical framings of eating disorders, paralleling the narratives of the eight women who contested bulimia. The six women also expressed conflicting feelings about bulimic practice and identities, wrestling with the stigmatized and pathologized positioning of bulimia. As these women - like all 36 people who took part in the larger study - had received treatment for their eating disorders, it is not surprising that they constructed their narratives through biomedical lenses and clinical terminologies (see also Eli, 2016), particularly as biomedicine provides culturally-dominant templates for interpreting the eating disordered experience, even beyond clinical contexts (Churruca et al., 2016). At the same time, their proclamations of bulimic identities did not preclude resistance to biomedical tropes (cf. Guilfoyle, 2001); indeed, their narratives, as the rest of this section and as the following sections will show, invoked bulimia as a diagnostic category in order to construct narratives of embodied selfhood.

The claiming of bulimic identity took different forms. Mirah, who recovered from bulimia after nearly two decades of eating disorder, began her interview by saying "first of all - I'm bulimic, ex-bulimic". Her self-identification as bulimic, past or present, wove through the rest of her narrative, and she spoke the words 'bulimia' and 'bulimic' more than any other participant. Mirah had anorexia in adolescence, but that disorder went unacknowledged and undiagnosed - an invisibility she attributed to her working class origins. Later, as a young adult, Mirah developed - and was diagnosed with bulimia. This 'naming', as she described it, was imbued with legitimacy, visibility, and belonging:

We really didn't know what anorexia is..... It was categorised as a disease of the top ten percent (financially), when I'm really not from the ten percent, my family is really not from the top ten percent, in an upper middle class like that. It was rather foreign. I also didn't know. I remember that afterwards, when I told myself, great, I'm bulimic - it moved me very much. There's a title, I know who I am, (and) I also belong to - I belong to some group, I have a name, it's possible to explain my behaviour, they researched the phenomenon - you understand, it seemed to me like, wow. (Mirah)

Psychiatric diagnosis, Lafrance and McKenzie-Mohr suggest (2013), ascribes legitimacy to individual experiences of social suffering, thereby serving as an authoritative means of confirming the distress of otherwise marginalized people (see also Eli, forthcoming). For Mirah, diagnosis led to a long-awaited acknowledgement of suffering and, thereby, to new self-knowledge.

While Mirah's story was unique, her use of 'bulimic' as shorthand for identity was not. Shiri, who 
said she was recovering but longing to practice binge eating, referred to her ongoing eating disorder as 'bulimia' throughout her narrative. When I asked her, "how do you define yourself in relation to the disorder?" - a question to which many other participants responded by describing their relationship to recovery, rather than diagnosis - she said: "I'm bulimic. I'll be bulimic my whole life". By contrast, another participant, Adi, who described herself as recovering, used the phrase 'eating disorder' throughout her narrative and did not use 'bulimic' as an adjective. However, she provided a chronology of her disorder, in which she foregrounded the rest of her narrative with the statement: "And then it became fresh and pure bulimia, of eating huge amounts of food all day and then vomiting it". Detailed depictions of binge eating and vomiting were, indeed, central to Adi's narrative, and she highlighted the metaphoric connections between these practices and her identity.

Despite the apparently clear use of the words 'bulimia' and 'bulimic', proclaiming bulimic identity was a loaded act, filled with contradictions and informed by social constructions of bulimia, binge eating, and psychiatric disorder. The participants were aware of the stigma attached to eating disorders, and to bulimia specifically, and proclamations of bulimic identity were, at times, tinged with shame. Navah, who developed bulimia after being hospitalized for anorexia, said it took years and the intervention of a friend - before she realized she had bulimia. The realization, she said, amounted to "disintegration", and although she began to describe herself as 'bulimic', it was an identity fraught with tension:

I, like, constantly live with the feeling that like, I'm bulimic now, and bulimia is anorexia's ugly sister. I'm bulimic because I, like, failed as anorexic. I'm bulimic because I, like, can't succeed in being anorexic. I'm bulimic because I want to keep some opening to return to anorexia, and I'm not really succeeding. (Navah)

Binary constructions of anorexic success and bulimic failure, as Burns (2004) suggests, echo broader societal framings of self-regulation and control as a means to desirable selfhood. A day before Navah and I met for our first interview, she sent a message to warn me that she was bulimic and not underweight; when I mentioned this message during the interview, Navah explained that she wanted to prevent disappointment. Along similar lines, when I first met with Angie, and she read the consent form (which featured the word 'anorexia'), she immediately told me she was bulimic. Angie, however, was severely emaciated. In clinical terms, she matched the diagnosis of anorexia. Yet she resisted it, claiming bulimia instead:

When they say 'anorexic' to me I'm like, I immediately (say), I'm not anorexic, I'm bulimic, and then there's a part of me that like, says like, don't give me this honour, I'm not, I'm not. But also, like, don't make me into what I'm not, and also like, I'm not ashamed of the fact 
that I'm bulimic, so don't say that I'm anorexic, okay? And also, sometimes I would want to be on the other side, a bit, like, because sometimes it, like, it, it prevents a lot of things from me, it destroys a lot of things... I can't stay over at home with my (younger) siblings because I can't binge there. (...) But I know that it's also an illusion, that the anorexic, too, destroys, and also - let's say I didn't have these problems of bingeing and vomiting, then I would have had other problems that arise, if I were on the other side. (Angie)

On one level, Angie's resistance to the adjective 'anorexic' paralleled other participants' resistance to the term. For example, one participant, who engaged in self-starvation and did not binge, said she resisted her anorexia diagnosis because she had not done enough to earn the 'title' of anorexia. Yet, in Angie's case, she not only resisted anorexia, but also claimed bulimia - whilst arguing, elsewhere in her narrative, against characterizations of bulimics as "bubbly" and "sexually active". The ambivalence Angie expressed about the "honour" accorded to anorexia was linked not to her diagnosis, but to the practice of binge eating, which she simultaneously cultivated and loathed. It was a practice that defined her identity, a practice she described as "part of me"; but it was also a practice that led to exclusion from her family home, and to years of repeated hospitalizations and occasional homelessness. Her sense of lacking "honour" lay in those contradictions.

But contradiction, ambivalence, and even shame, did not preclude distinction. Previous anthropological work has employed Bourdieu's (1984) concept of distinction to define the subject positions that women with eating disorders cultivate through (seemingly) "healthy eating" - a set of socially-desirable food-related practices that demonstrate conscious consumption and apparent selfcare, thus resonating with broader societal constructions of taste and class (Musolino et al., 2015: 19). In the present study, however, the distinction evoked in participants' narratives was unrelated to engagement in socially-desirable practices. On the contrary, participants cast their distinction as emanating from the subversive character of bulimic practice; their narratives, then, evinced a coexistence of shame and distinction. This co-existence was highlighted in Dinah's narrative. Dinah recovered after about a decade of eating disorder; she was diagnosed with both anorexia and bulimia, but defined her disorder as bulimia. When Dinah said that her husband and sisters occasionally joked about her mental health, and specifically about her time as an inpatient in a closed psychiatric ward, I asked about her experiences with stigma. Her response revealed an interweaving of shame and distinction, past-tense and present-tense - proclaiming eating disordered identity, qualifying and backtracking, proclaiming and qualifying again:

The disease has a stigma. Psychiatric hospitalization no doubt has (stigma).... (But) eating disorders sometimes have a positive stigma, even, like, there's something about it. I don't know. But I'm not terribly proud of it. (...) Sometimes there's something heroic about it, I 
think, about (saying) I was anorexic, I was bulimic. (...) It used to be my calling card. Today not at all. But sometimes I think about it, and it seems illogical that it happened. (Dinah)

\section{Bulimic being as distinct: contrasting bulimia with anorexia and with health}

Bulimic distinction was constructed within matrices that implicated other bodies and practices. As a diagnosis, bulimia is always-already relational, cast in opposition both to 'health' and to 'anorexia'. These binary constructions reappeared in the participants' narratives, where they distinguished and demarcated themselves as eating disordered or as bulimic, against actual or imagined others. When Adi spoke about watching a television news programme filmed at the ward where she had been hospitalized, she framed it through the binary of 'disordered' versus 'healthy'. The programme, she said, caused her great discomfort, particularly because her boyfriend watched it with her. It was not the intimacy of the disorder, on display, that made Adi uncomfortable; rather, it was the programme's discursive linking of eating disorders and fashion modelling, which, she thought, minimized her eating disorder in her boyfriend's mind:

There was a programme this week on channel 2, I think, about eating disorders - but the programme was so shallow because of the simple reason that it presented the pure connection between thin models and eating disorders. (...) Anyone can see beautiful models and say, wow, I want to be like her, but that's not the reason. (...) Anyone says, wow, I feel like being a model, but few girls - not few, today it's not at all few - but not everyone will say, okay, I'm doing everything and making all the sacrifices to be there. (Adi)

To be eating disordered, as Adi framed it, was to be committed to a vocation, to be set apart from others through force of will and dedication. Here, Adi did not distinguish between anorexia and bulimia: self-starvation, binge eating, and purging, and their attendant consequences, all formed a complex that equated "making all the sacrifices" - a distinct stance obscured by the 'normalizing' discourse of fashion modelling and the thin ideal.

A similar demarcation of 'eating disordered' from 'normal' also appeared in Shiri's narrative, albeit with a biologizing inflection:

It's not that everyone who sees a model and wants to look like her becomes anorexic or bulimic. You need to be born with something else, with some other understandings, I don't know. (...) Other people, normal (people), who weren't born with this defect, I don't know how you want to call it, an utterly non functioning serotonin gland, then they look, they eat what - they eat one (thing), eat two, or taste, and go home. Next time they'll taste, not taste, it doesn't matter that much. For me, this abundance, it blinds me. Other people, (normal) 
people, choose. (...) I don't know if it's genetic, but it's inborn. Like people who commit suicide. Not everyone can bring himself to commit suicide. It's inborn. (Shiri)

As Shiri framed it, eating disorders, like suicide, were reserved for people with unique capacities. A close friend of Shiri's committed suicide a few months before the interview, and this likely influenced her interpretation. But her choice of the term 'suicide' was not idiosyncratic. On a metaphoric level, in colloquial Hebrew, the phrase 'committing suicide over it' (lehit'abed al zeh) refers to acting with passionate determination for a cause, even at the cost of professional and social self-destruction. Although Shiri was speaking about literal suicide, these culturally loaded linguistic links between suicide and self-destructive sacrifice are notable.

As Adi's and Shiri's quotes demonstrate, binary constructions of 'anorexic' and 'bulimic' did not necessarily follow the expected lines of 'purity' and 'danger', to employ Squire's phrase. Participants often collapsed these diagnoses, speaking about both disorders as equal manifestations of the larger, and more fluid, category of eating disorder. Yet, as I discussed previously, framings of anorexia and bulimia through the lenses of honour and shame, or success and failure, permeated some participants' positioning of their own bulimic identities. This binary, however, also held other discursive possibilities. In her narrative, Mirah offered an alternative reading, one which challenged the supposed superiority of anorexia over bulimia:

We're more like frustrated anorectics, do you understand? Like, it seems that we don't have enough madness. We're not, we're also not like the compulsive eaters. We don't go all the way. That's why we suffer more, that's why it's also easier to talk to us (...) We do let ourselves feel the pain, but we can't bear it, and then we vomit it. And the anorexics and the compulsive eaters, they won't feel the pain. They go beyond. This one binges, that one starves herself. But we do, like, we want to live life, we try, we want to eat, but we can't contain it. That's why the bulimics - (my friend) and I always say, bulimics are cooler. I connect more to bulimics; (they're) less in denial, more approachable. (Mirah)

According to Mirah, bulimia stood apart from anorexia and compulsive eating by occupying a middle ground between disorder and sanity. Mirah cast the bulimic self as imbued with greater pain and suffering, implicitly facing life with greater bravery than her anorexic counterparts. She thus inverted the commonplace binary, positioning binge eating and purging, rather than self-starvation, as the ultimate form of self-mortification.

\section{From abnormal to untamed selfhood}

Although bulimia was relational, cast in binary contrasts, being bulimic amounted to more than not 
being 'normal' or not being anorexic. The participants used these binary contrasts as a platform for portrayals of identity, seamlessly transitioning from the description of difference to the delineation of the self. These transitions were apparent in participants' descriptions of binge eating and purging as practices that implicate both difference and unique subjectivity. Like many participants, including those who resisted the term 'bulimia', the women who described themselves as bulimic provided detailed descriptions of binge eating, unprompted by me. Dinah's description (see also Eli, 2015), loaded with value judgments, was typical of the genre: ${ }^{3}$

Today, when I tell people about it, they just feel disgusted. It's amounts that you cannot believe that a body, that a normal body of a human being can (contain).... (You eat) until you feel that you're torn, that you can't move anymore, and then the vomiting, which is incredibly releasing. (Dinah)

Dinah began by invoking disgust as the 'normal' reaction to the binge eating she used to find compelling. She then cast her body as set apart from 'normal' human bodies, the abnormality of her condition implicitly moving beyond her practice to encompass her embodied self, and concluded with the sharp sensations of acute pain and release. Dinah later drew on the 'abnormality' of her embodied self to describe who she was, at the height of her disorder:

Dinah: And I did everything, and I would go out in the evening, drink alcohol. I'm glad I didn't experiment with drugs, because I might have become addicted to that, too. Like, I really lived a wild lifestyle and - you know, it characterizes bulimics, promiscuity. I didn't do things - again, I didn't reach rock bottom, except for vomiting in the street, which is rock bottom. I remember I was on a trek in (Southeast Asia) and there was nowhere (to vomit), so I would eat, and I would find all sorts of dark corners next to trees, in which to vomit, or all sorts. But - it's a bit of sexual promiscuity, drinking, I mean, I lived a really wild life, relatively.

KE: Doesn't it bother you, that word, promiscuity? Because it's not - it's a loaded word, somehow.

Dinah: Umm, yes, because - no, it doesn't - I have no problem with this word... I read, I had a chance to read... all sorts of books somehow related to eating disorders, and they describe behaviours that are like, totally crazy. Drunk driving and drugs and cocaine and totally promiscuous sex. So I didn't reach such extremes, but relative to myself, a good (middle

\footnotetext{
${ }^{3}$ An excerpt of the quote that follows also appears in Eli (2015, p. 366).
} 
class) girl, ${ }^{4}$ relative to my sisters and my friends, I was promiscuous.

In this excerpt, Dinah discursively transitioned from framing herself as abnormal to framing herself as untamed. Although the sexualities of women defined as bulimic have been pathologized in the clinical literature (Burns, 2004), Dinah did not apologize for or seek to excuse her past practices; on the contrary, her self-portrayal was imbued with a positive sense of difference, as she separated herself from the conformity of her sisters and friends, and aligned herself with textual depictions of implicitly heroic bulimics, literary protagonists far removed from the secure, middle-class existence she was expected to lead.

A similar construction of untamed selfhood as opposed to conformist peers appeared in Navah's narrative. During one of her interviews, as Navah was lighting a cigarette, I commented on the apparent rarity of smoking in the Orthodox Jewish community of which Navah was part. Navah's reaction to this comment led to an exploration of self versus society, through the prism of her eating disorder.

KE: Cigarettes, it's not that common in your community, right?

Navah: Right.

KE: Especially not among girls.

Navah: But I also think that eating disorders are not a common thing in my community.

KE: You think (so)? Maybe it's just something they don't talk about that much?

Navah: Also, but I also read about it - I read about it, like, a study, that the more religious you are, the less of a chance there is that you'll be eating disordered.

KE: I think that -

Navah: I beat the statistics. (...) Listen, the religious community tends to ignore any problem there is... (it was) the biggest secret, like, my siblings don't know until today, like it was really the family's biggest secret and it was forbidden to tell it, and - umm, which is like, that's why I can imagine that there are other girls who are simply not talked about. (But) it seems to me that it's not really as common, really not as common (as in wider society). And the cigarettes, too. I was always a bit different. Like, I've smoked since high school. (...)

\footnotetext{
${ }^{4}$ Here, Dinah used a variation on the Israeli phrase yeled tov Yerushalayim - a good Jerusalem child (in the masculine) - which is used to describe a kind, innocent, and conforming person. Dinah, however, changed the phrasing to the feminine (yalda tova), and replaced the word 'Jerusalem' with the name of her hometown, which is known in Israel for its mainstream values and material affluence.
} 
KE: In what other ways are you different from your community, if you're willing to give examples?

Navah: Sex interests me much more than it interests other girls my age. I had many more sexual experiences than my friends. Like, you know, my friends didn't touch anyone, any guy, until their wedding night. And I, like, always wanted it, waited for it, and did it. Which was always an unusual thing. (...) I live on the border between worlds. (...) And the fact that I went to study (at art school) is an unusual thing in the religious landscape.

Navah framed her eating disorder as a marker of her essential - and positive - difference from other women in her community. Although she engaged with the possibility that eating disorders are underreported due to the secrecy that surrounds mental health issues in Orthodox communities, she reiterated that eating disorders really are rare among Orthodox women, discursively cementing her distinction by saying "I was always a bit different". Notably, when I asked for other examples of difference, Navah immediately spoke about her sexual experiences, invoking the ultimate social taboo for an unmarried Orthodox woman and fully owning her desires, without offering 'normalizing' explanations or expressions of regret. Presenting her enrollment at art school as the second example of difference, Navah alluded to a nonconformity that transcended the vestiges of 'rebelling' through smoking, bingeing and purging, and sexual activity. Navah's pursuit of higher education in the arts represented a substantive, intellectually and creatively liberating difference, one that placed her beyond the bounds of her peers' implicitly circumscribed lives.

In the participants' narratives, the nonconformity of bulimic practice emerged as an existential stance. Angie, who was acutely ill at the time of the study, explicitly defined herself as 'nonconformist' (in Hebrew, literally, "kicking the norms"); while she did not directly link her binge eating and purging practices to this self-definition, she said that the motivations underlying her eating disorder broke with social norms of appearance and attitude: "I'm a person who doesn't care what society thinks (...) I always go with what I feel". A more ambiguous self-definition was presented in Mirah's retrospective narrative. Mirah spoke of the conflict between dietary restriction and binge eating as encapsulating her competing desires for socially-conforming perfection and for self-expression (see also Eli, 2015; Eli, forthcoming). Within this framework, she described her past binge eating and purging as a release from dietary restriction, and as embodied resistance to the social strictures of Israeli womanhood. These strictures, she said, forced her to comply with an idealized notion of European femininity that belittled her Mizrahi ethnicity, and threatened to mould her into the repetitive, undifferentiated role of working mother: ${ }^{5}$

\footnotetext{
${ }^{5}$ The quote that follows also appears in Eli (forthcoming).
} 
In hindsight, it was something very very healthy, those binges, it was the most authentic thing I had in life. And I enjoyed them. I also enjoyed vomiting. I loved vomiting. There's something releasing like that.... I'm doing something like against nature.... It's something very forceful like that - no, childish - but there's something, a power, in that childishness. It's not that I'm accepting life with surrender. It means, (today) I tell my sister, yes, (Rachel), I accept you, I bow my head. Today I have a bad mood, I feel disgusting, but I bow my head, I accept that I'm feeling bad. (But) here the bulimic says, no! I don't accept it! I'm fighting, I'll go, I'll - do you understand? It's something standoffish, powerful, charming. Later you have to give it up. You say, come on, I'll be boring if I won't be bulimic. I'll be like everyone else. I'll go to work, come back, kids. Such boredom. Death, death, death. Here I have action. I eat, I vomit, I have fantasies that I'll have the perfect day, I'll have the perfect life. (Mirah)

Mirah cast herself as subverting the 'naturally' human, embodying resistance to her expected, gendered place in society through the act of binge eating and vomiting. Binge eating, she said, was "authentic", a practice through which she expressed herself and with which she identified (Eli, 2015); vomiting was "forceful", a practice through which she set herself apart, occupying a stance 'superior' to quotidian being. Together, they made for a powerful identity, transcendent in its lack of compromise.

Concepts of untamed selfhood were not limited to the explicit eschewing of a gendered, conformist social position. For Shiri, who used a nostalgic inflection when she described the "peak" of her bulimia, untamed selfhood was encapsulated in the breaking of social norms that her eating disorder entailed - seeking extreme social isolation in the name of immersing oneself, completely, in food: ${ }^{6}$

It was always food, nothing else. I didn't buy anything else. All my money - it all went on food. All the time, all the time. And at some stage I broke up with that boyfriend, I went (abroad), and I was there for a year and a half and it was a year and a half of ecstasy as far as my disease was concerned, because it was in full bloom and I was at the peak of enjoying it. Like, I'm really presenting it in a positive light because it gave me a lot, I mean, it's something that nothing else ever filled me up like that, like the food filled me up, (and) I don't think that anything will. (...) I lived alone, I was alone in my flat, always. The amounts of food I made there were astronomical, really. (Shiri)

Binge eating, as Shiri described it, was a practice in which she reveled, creating an autonomous self and space: perpetually alone, in another country, single and away from family and friends, seeking only food as company. Using absolutes and superlatives to describe her bulimic practice - "always",

\footnotetext{
${ }^{6}$ An excerpt of the quote that follows also appears in Eli (2015, p. 366).
} 
"all the time", "ecstasy", "full bloom", "astronomical" - she portrayed her experience as one of sensory extremes and continuous transcendence. Notably, Shiri reflected on the longing, "positive" tone she used, showing awareness that her self-presentation was not in keeping with the expected template, and then reinforced her narrative by saying that food had no equal in filling her up (see also Eli, 2015) - thereby, again, claiming her autonomy as an agent set apart.

Most participants spoke of their untamed selfhood in mundane contexts. In Adi's narrative, however, she portrayed her bulimic distinction as extending from extreme vomiting practices to an embodied sense of invulnerability and immortality. Describing her purging practices, she said:

You learn to be Einstein with this disease. If you don't want people to acknowledge it, they won't acknowledge it. You need to be a real champion. Listen, I started vomiting into bags, into rubbish bags, when no one saw I would take (them) out. You learn to vomit in the gutter. You learn to vomit into cups. You learn to vomit into bottles. You learn - there are ways, in the bushes, taking a bottle, drinking from it, vomiting. Who will follow you, who will care? No one really cares. (Adi)

The shock value of Adi's description was coupled with the positive superlatives she used - "Einstein" and "champion". These superlatives had a playfulness to them, but she did not use them sarcastically. As Adi enumerated the various forms of vomiting, she essentially provided evidence that the disorder involved the cultivation of specialized knowledge and skills. These unusual skills translated into an unusual embodiment, one which she described as 'superhuman':

As far as I was concerned, my body lived, was alive, breathed - I used to vomit blood, I didn't even pay attention to it. As far as I was concerned it was nothing. That means, I connected to my body in terms of it being omnipotent: I'd ride a motorcycle - I rode a 600 cubic centimetre motorcycle without a licence, I got a licence later, I didn't feel anything would happen to me. I rode mad horses, and I didn't feel that anything will happen to my body, even if it will fall, it will not bruise, because it will be fine, I will be fine, a sort of super-humanity. (Adi)

From descriptions of extreme vomiting to horseback riding, Adi narrated her literalizing of untamed selfhood through embodied practice. Adi's bulimia encompassed more than binge eating and purging; it included a sense of transcendence over and through the body, setting herself apart as superior and fiercely alive, her allusion to "super-humanity" capturing a nearly euphoric sense of distinction. 


\section{Conclusion}

The participants' narratives of bulimic identities demonstrate the need to go beyond accepted tropes of body image and socially desirable practices of dietary restriction and exercise in order to understand the diversity of the eating disordered experience. For the participants, bulimia was not merely anorexia's 'other' (Burns, 2004); the relationships the participants described between bulimia and anorexia were complex, and at times contradictory. While some participants spoke of anorexia as superior, they also collapsed the boundaries between the two disorders, or reversed the accepted hierarchy. It is important to note, moreover, that the coexistence of inferiority and superiority - or degradation and exaltation - is not unique to the bulimic experience; rather, it is a theme that reappeared in the narratives of participants who identified as anorexic and engaged in self-starvation, and is part of the greater ambivalence that characterizes the eating disordered experience (Eli, 2014). I have argued previously that the existential meanings of binge eating are crucial for understanding why eating disorders persist over time (Eli, 2015); I would like to suggest now that an exploration of bulimic identities is equally important in shedding light on the long-term maintenance of bulimia as a self-defining practice. Namely, an analysis of the valued subject positions that some women construct through bulimia adds to our understanding of the "maintaining mechanisms" still missing from cognitive-behavioural models of bulimia (Fairburn et al., 2003: 515), wherein binge eating and purging are positioned as a reaction to emotional stimuli and dietary restriction, rather than as valued practices (Murphy et al., 2010).

As the participants' narratives demonstrated, the claiming of bulimic identity was not merely the acceptance of a diagnosis. In describing their eating disorder, and themselves, through the words 'bulimia' or 'bulimic', the participants aligned bulimia with concepts of distinct selfhood. To be bulimic was to be situated as 'abnormal'; but this 'abnormality', albeit a source of social stigma and shame, held meanings that went beyond pathology. Through the claiming of bulimic identity, participants positioned themselves as subversive, non-conforming subjects, who acted against gendered and classed expectations - and even against the limitations of the body. The participants' resituating of bulimic identity as subversive shares some commonalities with fat acceptance groups and activist movements, where stigmatized and pathologized fat bodies are reframed as nonconforming, rebellious, and politically subversive (LeBesco, 2004; Mitchell, 2005; Owen, 2015). However, in contrast to the communal, and often publicly articulated, projects of resituating evident in fat acceptance contexts, for the women who participated in this study, resituating the bulimic self as subversive was a largely solitary process. While this difference may be due to divergences between the biomedical and social classifications of fatness and bulimia, it also highlights the historical situatedness of the study. In the literature on fat acceptance (e.g. LeBesco, 2004; Pausé, 2012), as in the literature on pro-anorexia (e.g. Dias, 2003; Fox, 2005), online spaces emerge as pivotal locations for the articulation of non-conforming identities and communal politics of the body. In this study, of 
the six women who identified as bulimic, only the youngest two - who were in their early $20 \mathrm{~s}$ in 2005-2006 - took part in (Hebrew-language) online eating disorder communities; these communities were not available when the oldest two participants experienced their eating disorder at its most acute (from the late 1980s into the 1990s). Given the proliferation of social media and of online eating disorders communities in the last decade, it is possible that contemporary and emerging processes of bulimic subjectification might have a communal, and even overtly politicized, dimension.

While the participants' processes of resituating bulimic identities as subversive may have been largely solitary, they also had a relational dimension. The participants constructed bulimic personhood in relation to others - and to the imagined, conformist lives the participants themselves might have led had they not developed this disorder. Like people who identify as anorexic (Eli, 2014), the participants expressed the implicit value of being set apart from the social 'mould' through their eating disorder; but while anorexia appeals to values of goodness, purity, and righteousness (see O'Connor and Van Esterik, 2015; Warin, 2010), bulimia appeals to values of risk-taking, fierce living, and rebelliousness. In defining bulimic selves as positively untamed, the participants described a subversive model of idealized selfhood - a model that is striking in its individualism, particularly in the context of Israeli society, which has long been considered collectivist (Oyserman, 1993). Yet the participants' valuing of rebellious individuality was far from idiosyncratic: it reflected broader tensions within Israeli society, whose simultaneous forces of collectivism and neoliberalism, ongoing military conflict and expanding capitalism, push citizens into oscillating, strategic assertions of collective and individual identity (Oyserman, 1993; Birenbaum-Carmeli, 2001). As other scholars have noted, while institutional participation and collective belonging are highly valued in Israeli society, citizens are also expected to distinguish themselves as individuals through risk-taking, transformation, and achievement (Noy, 2004; Sasson-Levy, 2008). Thus, although young Jewish Israelis are trained to "crystallize" into collaborative, emotionally bonded collectives in the total institutions of primary and secondary school and the military (Katriel, 1988), they speak of these highly structured experiences in individualist terms of self-development and self-fulfillment (SassonLevy, 2008). These expressions of individualism, however, are socially sanctioned; in translating a compulsory collective experience like military service (Sasson-Levy, 2008), or an informal rite-ofpassage like the post-military trekking journey (Noy, 2004), into individual terms, young Israelis do not express a rejection of collectivism but rather demonstrate the elision of collective and individual interests - and the ease with which valued individuality may be achieved through conforming to socially dominant institutions.

The bulimic distinction the participants described emerged against the background of participation in total institutions, including an elite secondary school, a kibbutz, a youth movement, and the military. But this participation was fractured, compromised by marginalization, difference, and exclusion. It was therefore through enacting an alternative, socially indexed mode of subversive selfhood that the 
participants embodied valued individuality - in some cases, directly challenging gendered, religious, classed, and ethnic perimeters of 'normal' subjectivity. Like their Israeli anorexic counterparts, who, according to Gooldin (2008), draw on militarized narratives to construct a heroic subjectivity through hunger, the participants constructed bulimic distinction through drawing on wider Israeli narrative repertoires, both mainstream and alternative, that value (masculine) risk and rebellion as markers of leadership (cf. Katz, 2009).

The participants' framings of bulimia were embedded in local values and narratives of citizenship that extend beyond the narrative templates of shame, abjection, and femininity against which bulimia has been examined. Their constructions of bulimic distinction highlight the need for anthropological work that situates bulimia not as a footnote to anorexia, but as a structurally and culturally meaningful condition in its own right. As most anthropological and cognate research on eating disorders has been limited to analyses of anorexia in European, North American, and Australian contexts, future work should strive to broaden the analytic lens both conceptually and geographically, accounting for the intersections of eating disordered practices and local specificities as they foster articulations of bulimic identities.

\section{Conflict of interest statement}

The author states that there is no conflict of interest.

\section{References}

Alpers, Georg W., and Brunna Tuschen-Caffier 2002 Negative Feelings and the Desire to Eat in Bulimia Nervosa. Eating Behaviors 2(4): 339-352.

American Psychiatric Association 1987 Diagnostic and statistical manual of mental disorders, third edition, revised (DSM-III-R). Washington, D.C.: American Psychiatric Publications, Incorporated.

American Psychiatric Association 2013 Diagnostic and statistical manual of mental disorders, fifth edition (DSM-5). Washington, D.C.: American Psychiatric Publications, Incorporated.

Birenbaum-Carmeli, Daphna 2001 Between Individualism and Collectivism: The Case of a Middle Class Neighbourhood in Israel. International Journal of Sociology and Social Policy 21(11/12): 1-25.

Bordo, Susan 2003 Unbearable Weight: Feminism, Western Culture, and the Body. London: University of California Press.

Bourdieu, Pierre 1984 Distinction: A Social Critique of the Judgement of Taste. Harvard 
University Press.

Braun, Virginia and Victoria Clarke 2006 Using Thematic Analysis in Psychology.

Qualitative Research in Psychology 3(2): 77-101.

Brooks, Anna, Amanda LeCouteur, and Julie Hepworth 1998 Accounts of Experiences of Bulimia: A Discourse Analytic Study. International Journal of Eating Disorders 24(2): 193205.

Broussard, Brenda B. 2005 Women's Experiences of Bulimia Nervosa. Journal of Advanced Nursing 49(1): 43-50.

Burns, Maree 2004 Eating like an Ox: Femininity and Dualistic Constructions of Bulimia and Anorexia. Feminism \& Psychology 14(2): 269-295.

Churruca, Kate, Jane M. Ussher, and Janette Perz 2016 Just Desserts? Exploring Constructions of Food in Women's Experiences of Bulimia. Qualitative Health Research: 1049732316672644.

Dias, Karen 2003. The Ana Sanctuary: Women's Pro-Anorexia Narratives in Cyberspace. Journal of International Women's Studies 4(2): 31-45.

Eddy, Kamryn T., David J. Dorer, Debra L. Franko, Kavita Tahilani, Healther ThompsonBrenner, and David B. Herzog. 2008 Diagnostic Crossover in Anorexia Nervosa and Bulimia Nervosa: Implications for DSM-V. American Journal of Psychiatry 165(2): 245-250.

Eddy, Kamryn T., Pamela K. Keel, David J. Dorer, Sherrie S. Delinsky, Debra L. Frando, and David B. Herzog. 2002 Longitudinal Comparison of Anorexia Nervosa Subtypes.

International Journal of Eating Disorders 31(2): 191-201.

Eli, Karin 2014 An Embodied Belonging: Amenorrhea and Anorexic Subjectivities. Medicine Anthropology Theory 1(1): 53-80.

Eli, Karin 2015 Binge Eating as a Meaningful Experience in Bulimia Nervosa and Anorexia Nervosa: A Qualitative Analysis. Journal of Mental Health 24(6): 363-368.

Eli, Karin 2016 'The Body Remembers': Narrating Embodied Reconciliations of Eating Disorder and Recovery. Anthropology \& Medicine 23(1): 71-85.

Eli, Karin forthcoming Striving for Liminality: Eating Disorders and Social Suffering. Transcultural Psychiatry.

Elran-Barak, Roni, Maya Sztainer, Andrea B. Goldschmidt, Scott J. Crow, Carol B. Peterson, Laura L. Hill, Ross D. Crosby, Pauline Powers, James E. Mitchell, and Daniel Le Grange 2015 Dietary Restriction Behaviors and Binge Eating in Anorexia Nervosa, Bulimia Nervosa and Binge Eating Disorder: Trans-Diagnostic Examination of the Restraint Model. Eating Behaviors 18: 192-196.

Fairburn, Christopher G., Zafra Cooper, and Roz Shafran 2003 Cognitive Behaviour Therapy for Eating Disorders: A "Transdiagnostic" Theory and Treatment. Behaviour Research and Therapy 41(5): 509-528. 
Fox, Nick, Katie Ward, and Alan O'rourke 2005 Pro-Anorexia, Weight-loss Drugs and the Internet: An 'Anti-Recovery' Explanatory Model of Anorexia. Sociology of Health \& Illness 27(7): 944-971.

Gooldin, Sigal 2008 Being Anorexic. Medical Anthropology Quarterly 22(3): 274-296.

Gremillion, Helen 2003 Feeding Anorexia: Gender and Power at a Treatment Center. London: Duke University Press.

Guilfoyle, Michael 2001 Problematizing Psychotherapy: The Discursive Production of a Bulimic. Culture \& Psychology 7(2): 151-179.

Hepworth, Julie 1999 The Social Construction of Anorexia Nervosa. London: Sage.

Heywood, Leslie 1996 Dedication to Hunger: The Anorexic Aesthetic in Modern Culture. London: University of California Press.

Katriel, Tamar 1988 Gibush: A Study in Israeli Cultural Semantics. Anthropological Linguistics 30(2): 199-213.

Katz, Gideon 2009 The Secular Hero: The Spirit of Individualism in the Israeli Discourse about Secularism. Journal of Modern Jewish Studies 8(2): 133-149.

Lafrance, Michelle N., and Suzanne McKenzie-Mohr 2013 The DSM and its Lure of Legitimacy. Feminism \& Psychology 23(1): 119-140.

Lavis, Anna 2011 The Boundaries of a Good Anorexic: Exploring pro-Anorexia on the Internet and in the Clinic. Unpublished doctoral dissertation. Goldsmiths, University of London.

Lavis, Anna 2014 Alarming Engagements? Exploring Pro-Anorexia Websites in/and the Media. In Obesity, Eating Disorders and the Media. Karin Eli and Stanley Ulijaszek, Eds. Farnham: Ashgate, 11-36.

Lavis, Anna 2016 A Desire for Anorexia: Living through Distress. Medicine Anthropology Theory 3(1): 68-76.

LeBesco, Kathleen 2004 Revolting bodies?: The struggle to redefine fat identity. University of Massachusetts Press.

Lester, Rebecca 1997 The (Dis) Embodied Self in Anorexia Nervosa. Social Science \& Medicine 44(4): 479-489.

Lester, Rebecca 2007 Critical Therapeutics: Cultural Politics and Clinical Reality in Two Eating Disorder Treatment Centers. Medical Anthropology Quarterly 21(4): 369-387.

Lester, Rebecca 2014 Health as Moral Failing: Medication Restriction among Women with Eating Disorders. Anthropology \& Medicine 21(2): 241-250. 
Mitchell, Allyson 2005 Pissed off. In Fat: The Anthropology of an Obsession. Kulick, Don and Meneley, Anne, Eds. New York: Penguin: 211-25.

Murphy, Rebecca, Suzanne Straebler, Zafra Cooper, and Christopher G. Fairburn 2010 Cognitive Behavioral Therapy for Eating Disorders. Psychiatric Clinics of North America 33(3): 611-627.

Musolino, Connie, Megan Warin, Tracey Wade, and Peter Gilchrist 2015 "Healthy Anorexia": The Complexity of Care in Disordered Eating. Social Science \& Medicine 139: $18-25$.

Noy, Chaim 2004 This Trip Really Changed Me: Backpackers' Narratives of Self-Change. Annals of Tourism Research 31(1): 78-102.

O’Connor, Richard A., and Penny Van Esterik 2015 From Virtue to Vice: Negotiating Anorexia. Oxford: Berghahn Books.

Owen, Lesleigh J. 2015 Monstrous Freedom: Charting Fat Ambivalence. Fat Studies 4(1): 113.

Oyserman, Daphna 1993 The Lens of Personhood: Viewing the Self and Others in a Multicultural Society. Journal of Personality and Social Psychology 65(5): 993.

Pausé, Cat 2012 Live to tell: Coming Out as Fat. Somatechnics 2(1): 42-56.

Sasson-Levy, Orna 2008 Individual Bodies, Collective State Interests: The Case of Israeli Combat Soldiers. Men and Masculinities 10(3): 296-321.

Scheper-Hughes, Nancy, and Margaret M. Lock 1987 The Mindful Body: A Prolegomenon to Future Work in Medical Anthropology. Medical Anthropology Quarterly 1(1): 6-41.

Shohet, Merav 2007 Narrating Anorexia: "Full" and "Struggling" genres of Recovery. Ethos 35(3): 344-382.

Squire, Sarah 2002 The Personal and the Political: Writing the Theorist's Body. Australian Feminist Studies 17(37): 55-64.

Squire, Sarah 2003 Anorexia and Bulimia: Purity and Danger. Australian Feminist Studies 18(40): 17-26.

Thompson, Becky Wangsgaard 1992 “A Way Outa No Way”: Eating Problems among African-American, Latina, and White Women. Gender \& Society 6(4): 546-561.

Warin, Megan 2010 Abject Relations: Everyday Worlds of Anorexia. London: Rutgers University Press.

World Health Organisation 1992 The ICD-10 Classification of Mental and Behavioural Disorders: Clinical Descriptions and Diagnostic Guidelines. Geneva: World Health Organization. 